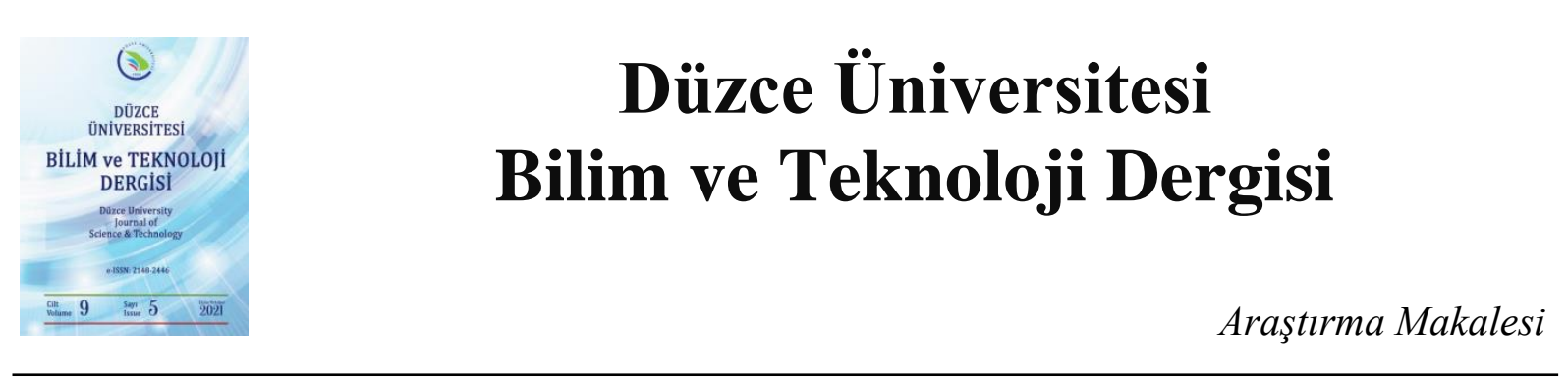

YHTD’lerin Değerlendirilmesinde Yeni Bir Yöntem

\author{
Hakan KARACA ${ }^{\text {a,* }}$ \\ ${ }^{a}$ Mimarlık Bölümü, Mimarlık Fakültesi, Niğde Ömer Halisdemir Üniversitesi, Niğde, TÜRKIYYE \\ * Sorumlu yazarin e-posta adresi: hakan.karaca@ohu.edu.tr \\ DOI: $10.29130 /$ dubited.719224
}

\begin{abstract}
Öz
Yer hareketi tahmin denklemlerinin sayılarının günden güne artması (YHTD), geliştirme aşamasında kullanılan verilerin artması ve buna paralel olarak denklemlerin daha karmaşık hale gelmesi, kullanıcılar açısından kolaylık değil daha çok külfet getirmiştir. Sismik tehlike analizi (STA) için hangi denklemin daha uygun olduğu ve daha kesin sonuçlar verebileceği konusu bir süredir kullanıcıları meşgul etmekte, denklem geliştiricileri ise denklemlerin geçerlilik koşulları konusunda zorlamaktadır. Denklemlerin uzaklık, deprem büyüklüğü ve diğer parametrelere bağlı değişken performansları ve özellikle belirsizlikleri, denklemlerin seçimi konusunda kullanıcıları mantık ağacı gibi yöntemleri geliştirmeye sevk etmiştir. Ancak bu yöntemle, belirli sayıda YHTD seçimi ile sadece tek YHTD seçilmesinin oluşturabileceği belirsizlik ve yanlış tercih olasılığı en aza indirilmeye çalışılmıştır. Ancak, şurası bir gerçek ki bu yönteminde yaklaşık yöntem olduğu ve en gerçekçi sonucu değil ancak en yakın sonucu verdiği bilinerek, yeni çözümler sunma amacı ile çalışmalar devam etmektedir. Bu çalışmada da, böyle bir bakış açısı ile tamamıyla yeni bir yöntem olan eşivme eğrileri ile uyumluluk yöntemi kullanarak, hâlihazırda geliştirilmiş denklemler değerlendirilmiştir. Ayrıca denklemlerin performansı diğer denklemlerle karşılaştırılarak yerel etkilere de vurgu yapılmıştır. Bu yöntemle, depremlerin yıkıcı etkilerinin daha yüksek olduğu alanlarda ki performansının önemi ön plana çıkartılarak yapılan değerlendirmenin, en doğru denklemin seçimi açısından önemi vurgulanmıştır.
\end{abstract}

Anahtar Kelimeler: Yer hareketi tahmin denklemi, Eşivme ĕgrileri, Harita benzeşim katsayısı, Artık

\title{
A New Method for the Evaluation of GMPEs
}

\begin{abstract}
Ever-increasing number of Ground Motion Prediction Equations (GMPEs), the databases used to develop GMPEs and the associated complexity of the functional forms, brought more burden over the shoulders of the users. The issues in the selection of the most appropriate GMPE for a seismic hazard analysis (SHA) gives the users hard time and forces the developers about the validity requirements of their GMPEs. Varying performances of GMPEs with respect to distance, magnitude and other parameters and especially different levels of uncertainties, urged users to find ways such as logic tree to reduce uncertainties. Only through the introduction of such methods, the uncertainty and the outright errors caused by choosing a single equation is minimized by the selection of a number of equations. However, knowing that the introduction of such a method is also an approximation and it doesn't yield the exact answer but only the approximation, studies are being conducted to find out better solutions. In this study, looking from the same angle to the problem, a new method is proposed which rely on the comparison of iso-acceleration maps developed by the measurements and the predicted values by GMPEs. In addition, the performance of each GMPE is compared and the locality of the GMPEs are stressed. By the introduction of the new method, the importance of the evaluation of GMPEs in their prediction performances of ground motion parameters closer to the earthquake epicenters in the overall evaluation of GMPEs for their appropriateness for the considered area.
\end{abstract}

Keywords: Ground motion prediction equation, Isoseismal contours, Map similarity index, Residuals

Geliş: 13/05/2021, Düzeltme: 20/06/2021, Kabul: 25/06/2021 


\section{GIRIS}

Sayıları 100leri aşan [1] ve artık katalogları oluşturulmaya başlanan yer hareketi tahmin denklemleri, içerdiği girdilerin çeşitliliği ve her bir girdinin tahmin edilen yer hareketi büyüklüğü ile karmaşık bağıntılarla ilişkilendiği göz önüne alındığında, uzun bir süre daha araştırma konusu olmaya devam edecektir. Denklemin oluşturulmasında ki esas amacın, deprem dalgalarının yayılmasını modellemek ve yapıların karşılaşabileceği yer hareketi büyüklüklerini hesaplamak olduğu ve deprem dalgalarına yakınlık ne kadar artarsa, yapıların maruz kalacağı deprem etkilerinin büyüklügünün de o kadar artacağı göz önüne alınırsa, denklemlerin özellikle maruziyet mesafesine göre daha hassas olmaları beklenir. Ancak hali hazırda geliştirilen denklemlerin böyle bir önceliği ve hassasiyeti olmadığı gibi, zaten denklemlerin geliştirilebilmesi için yerel ölçekte oluşturulan veri tabanlarının da ağırlıklı büyük depremlerin kısa mesafe etkilerini yansıtacak şekilde oluşturulması birçok yer için mümkün değildir [2]. Hâlihazırda kuvvetli yer hareketi modellerinin tamamı büyük depremleri kapsamakla birlikte [1], yıkıcı depremlerin büyük ve yakın mesafelerden etki ettiği gerçeği karşısında, bahsi geçen denklemlerin de aslında amaca tam olarak hizmet edip etmediği sorgulanabilir.

Böyle bir durumda, geliştirilen denklemlerin büyük bir kısmının büyük depremlerin kısa mesafelerdeki etkileri açısından duyarlılığının olmadığı ve aslında kısa mesafe etkilerinin çok önemli olduğu büyük depremlerinin etkilerinin hesaplanması açısından zayıf kalabileceği öngörülebilir. $\mathrm{Bu}$ durum ise, denklemlerin en başta geliştirilme amacı olan depremlerin yıkıcı etkisinin öngörülebilmesi amacı ile tam olarak bağdaşmamaktadır. Yani, eğer yapılara gelebilecek büyük yer hareketi etkilerini ancak küçük yer hareketlerinden elde ettiğimiz bilgiler 1şı̆̆ında öngörebiliyorsak [3], bu denklemlerin geçerliliği her zaman sorgulanmaya açık olacaktır. Öyleyse, denklemlerin geliştirilmesinde veya hâlihazırdaki denklemlerin değerlendirilmesinde takınılması gereken yaklaşım, bu denklemlerin büyük yer hareketlerini tahmin edebilme yetisinin öncelikli olarak irdelenmesi olmalıdır. Aslında denklemlerin gerçek depremlerin yayılma örüntülerini her biri için ayrı ayrı tahmin edip edemediği hakkında birçok çalışma bulunmakla birlikte [4], veri tabanında sadece büyük depremlerin, örneğin moment büyüklüğü $6.0^{\prime}$ dan büyük olan depremlerin, sadece kısa mesafelerde nasıl bir yayınım örüntüsüne sahip olduğu ile ilgili çalışma neredeyse hiç bulunmamaktadır [1].

Buna birde, küçük depremlerin uzun mesafelerde, sayısal depremölçerler tarafından kaydedilemiyor olması, ancak büyük ölçekli depremlerin göreli olarak uzak mesafelerde kayıtlarının bulunması nedeniyle oluşan veri yanlılığı nedeniyle [5], küçük depremlerin daha kısa mesafelerde sönümlendiği gibi bir yanılgının oluştuğu eklenirse, büyük depremlerin etkilerini modellemenin hangi kısıtlarla karş1 karşıya olduğu anlaşılabilir. Böyle bir durumda veri tabanı deprem büyüklükleri ve mesafeleri açısından benzeş olan denklemlerin, verilerdeki yanlılığın azalması nedeniyle gerçek yayılma örüntülerini daha başarılı modelleyebileceği ve açıktır.

Kısaca özetlenen sorun ile ilgili olarak eldeki veri tabanları ile yapılabileceklerin sınırlı olduğu ancak büyük yer hareketlerinin daha çok hasar verdirdiği kısa mesafelerdeki etkisini ölçebilme yetisinin daha önemli olarak değerlendirileceği yeni bir yöntemin gerekli olduğu sonucu çıkar. Bu çalışmanın amacı da böyle bir yöntem geliştirilmesi ve bu yönteminde hâlihazırda kabul gören YHTD değerlendirme yöntemlerine seçenek olarak sunulmasıdır. Bu amaç doğrultusunda, denklem artıklarının deprem büyüklügü ve mesafe kısalığı oranında büyütülerek değerlendirilmesi yapılmış, sonrasında aday denklemler kullanılarak oluşturulan eş-ivme haritaları ile 17 Ağustos 1999 İzmit Depremi ve 12 Kasım 1999 Düzce depremlerinin etkileri modellenerek geliştirilen eş-ivme haritaları karşılaştırılmıştır. 


\section{A. İZMIT ve DÜZCE DEPREM KAYITLARI}

Verilerin elde edilmesinde bütünlüğün sağlanması için Afet ve Acil Durum Başkanlığı [6]'nın kayıtlarına başvurulmuştur. İzmit depremi için 23 farklı istasyondan elde edilen kayıtlar ve Düzce depremi için de 19 farklı istasyondan elde edilen kayıtlar derlenmiş ve toplamda 42 adet kayıt çalışma için işlenmiştir. Şekil 1'de kayıtların elde edildiği istasyonların dağılımını gösterir haritalardan da anlaşılacağı üzere geniş bir alandan toplanan veriler, genelde ülkemizin batısındaki istasyonlardan elde edilmiş olup, özellikle fay kırıkları çevresinde yoğunlaşmıştır.

Derlenen kayıtlardan elde edilen kuzey-güney ve doğu-batı yönlü verilerin üssel ortalaması denklemler için ivme girdisi olarak kullanılmıştır. Bütün kayıtlar için taban düzeltme işlemi uygulanmış ve gürültüden arındırmak amacıyla da değişken alçak ve yüksek frekans sınırları eşliğinde 4-kutuplu Butterworth sügeci ile işlenmiş̧ir [7]. Uygulanan işlemler sonunda, YHTD kullanılarak elde edilen ivme-periyot dağılımları ile karşılaştırmak üzere, ivme-periyot dağılımları üretilmiştir.
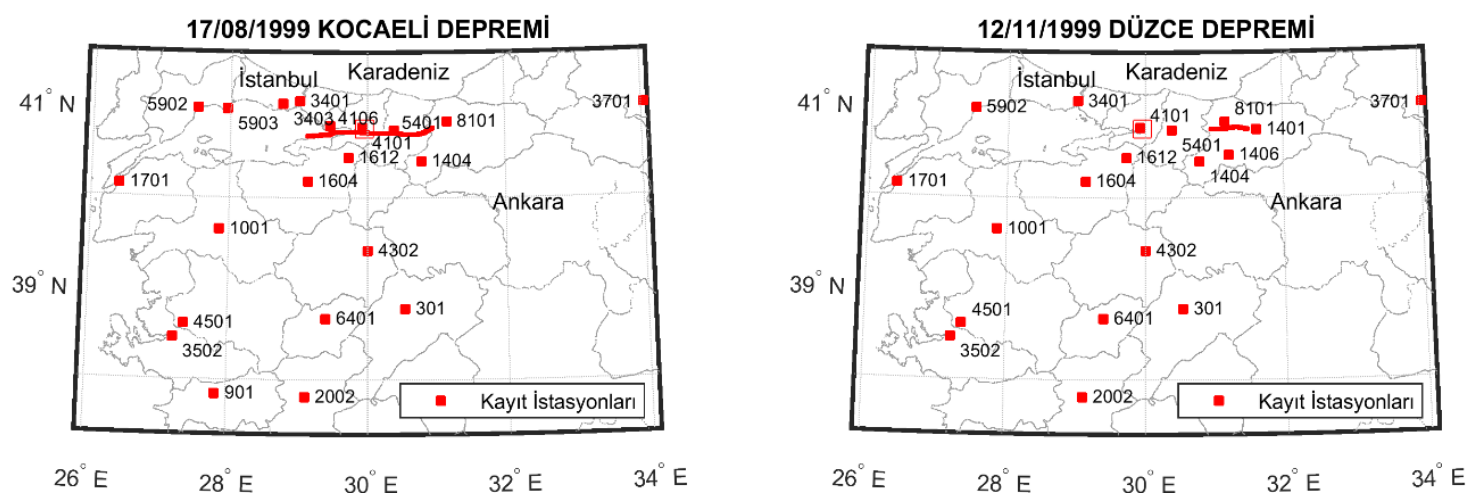

Şekil 1. İzmit ve Düzce deprem kayıtlarının elde edildiği sismik gözlem istasyonları [6].

Zaman ortamındaki ivme verilerinin yanı sıra PGA değerleri de aynı kayıtlardan derlenmiş, Sandıkkaya vd. [7] tarafından derlenen $\mathrm{V}_{\mathrm{s} 30}$ değerleri belirlendikten sonra, denklemlerin ana girdilerinden deprem kırığına en yakın yatay mesafe olarak tanımlanan $R_{j b}$ değerleri de hesaplanmıştır. Her iki depreminde yanal atımlı faylar üzerinde meydana gelmesinden dolayı, fay terimleri bulunan denklemler için sadece yanal atımlı fay verileri kullanılmıştır.

\section{B. YER HAREKETI TAHMIN DENKLEMLERİ}

Güncel denklemlerin hazırlanması sırasında kullanılan ergodik yaklaşım, yani bir yer hareketinin etkisinin konum ve zamandan bağımsız olarak, aynı olduğu savı, depremin yayılmasının yerel koşullara bağlı olup olmadığı irdelenmeden geliştirilmiştir. Aslında Bard vd. [8] esas sorunu ortaya koymuş ve depremin yayılma güzergâhı üzerinde bulunan dipkaya yapısının bile deprem enerjisinin yayılma ve sönümlenmesini keskin biçimde etkilediğini ve dolayısıyla yayılma değişkenliğinin en küçük sismotektonik birimde bile değişkenlik göstereceğini belirtmiştir. Böylesine bir değişkenliğin bulunduğu ve en küçük sismotektonik birim alanda bile yayılma farkl1lıkları bulunabileceğini göz önüne alarak bir çalışma yapmak ve bu durumu da aslında bir kısıt şeklinde düşünerek çalışma yapmak ve farklılıkları da nitel olarak tanımlayıp, nicel olarak da gösterebilmek gerekir [9]-[12]. Özellikle istasyonların sayısının hemen her yerde artması, duyarlılıklarının yükselmesi sayesinde deprem yayılma modellerinin yerel ölçekte geliştirilebilmesi ve yerelliğinin (non-ergodicity) sayısal olarak ifade edilebilmesi Kotha vd. [13] sayesinde aslında yayılma biçimi değişkenliğinin istasyonlar arasında bile diğer değişkenliklere göre daha fazla olabileceği gösterilmiştir [14]. Buna bir de denklemlerin karmaşık değişkenleri ile birlikte veri tabanlarının bu değişkenlerle uyumluluğu ile ilgili sorunlarda eklendiği zaman hangi denklemin nerede kullanılıp kullanılamayacağı ile ilgili çok değişkenli bir sorun ile karşsı karşıya kalırız [15],[16]. Bu bilgiler 1şığında, yerel denklemlerin yerel 
depremlerin yayılma desenini daha kesin ve daha az belirsizlikle modelleyebileceği de düşünülmelidir [17].

Çalışmanın amacının sunulacak olan yeni yöntemlerin tanıtımı olması nedeniyle de, seçilen denklemlerin detaylı bir irdelenmesine gerek duyulmamış, sadece yerelliği ve uygulamadaki yaygınlığı göz önüne alınarak, Kalkan ve Gülkan [18] (KG04), Özbey vd. [19] (OB04), Akkar ve Cagnan [20] (AC10) seçilmiştir. Bu üç denklemin yanısıra, geliştirme aşamasında yerel verilerinde kullanıldığ 1 Akkar ve Bommer [21] (AB10), Akkar vd. [22] (ASB14) tarafindan Avrupa ve Ortadoğu için geliştirilen denklemlerde aynı yöntemle karşılaştırma amaçlı olarak değerlendirilecektir. $\mathrm{Bu}$ denklemlerin hepsinde de bu çalışmada kullanılan kayıtlar kullanılmış ancak veri tabanlarının kapsama alanının değişken olması nedeniyle kullanılan kayıtların sayısı ve niteliğinin farklı olduğu gözlemlenmiştir.

Tablo 1. YHTD veritabanı özellikleri.

\begin{tabular}{lllll}
\hline YHTD & Veri tabanı Kayıtları & Deprem/Kayıt & Veri tabanı & Veri tabanı \\
\hline AC10 & Türkiye & $137 / 433$ & $3.5-7.6$ & $0-200$ \\
\hline KG04 & Türkiye & $57 / 112$ & $4.0-7.6$ & $0-250$ \\
\hline OB04 & Marmara Bölgesi & $17 / 195$ & $5.0-7.4$ & $0-100$ \\
\hline ASB14 & Avrupa ve Ortadoğu & $178 / 695$ & $4.0-7.6$ & $0-200$ \\
\hline AB10 & Avrupa ve Ortadoğu & $131 / 532$ & $5.0-7.6$ & $0-100$ \\
\hline
\end{tabular}

Yukarıda bahsi geçen yerellik ve veri yanlılığı bağlamında, Tablo 1'de gösterilen veri tabanı özellikleri incelendiğinde, OB04 ve AB10 veri tabanlarının depremlerin büyüklüğü ve mesafe açısından daha odaklı olduğu, ancak verilerin yerelliği açısından OB04'ün öne çıktığı belirtilmelidir. Kullanılan üç yerel denklemde performans karşılaştırmalarının yapıldığı birçok çalışmaya konu olmuş [23],[24] ve YHTD karşılaştırmalarında yer almıştır. Kalabalık bir veritabanı ile yapılan değerlendirmelere göre aslında öne çıkamayan OB04 ve KG04 denklemlerinin ayrıca Izmit ve Düzce depremlerinin yayılma modellerinin değerlendirildiği çalışmalarda da performansları test edilmiş [25],[26] ve özellikle KG04 ve OB04'ün kısa mesafelerde yüksek sönümlenme oranına sahip bu iki depremin modellenmesinde değerlendirilebileceği sonucuna varılmıştır. Aslında veritabanları incelendiğinde, her bir denklemin geliştirilme amacı da öngörülebilir. Böyle bir çalışma için İzmit ve Düzce depremlerinin temsil oranının en yüksek olduğu veritabanına sahip denklemin daha başarılı olması beklenebilir ki aslında bu iki depremin kendine has özelliklerinin defalarca vurgulandığ çalışmalara bakılırsa [27[,[28] böyle bir durum beklenmelidir.

\section{YÖNTEM}

En büyük ivmelerin ve aynı zamanda en yakın istasyonlardan elde edilen verilerin daha doğru tahmin edilebilmesi ölçütünün yanı sıra, bu değerlerin yakın coğrafya üzerindeki dağılımının da daha doğru tahmin edilebilmesi de önemli bir ölçüttür. Yüksek ivme değerlerinin daha doğru tahmini, bu değerlerin coğrafi dağılımı göze alınmadan yapılırsa tahmin yaklaşımı bir yönüyle eksik kalır çünkü bu değerlerin de mekânsal etki açısından önem derecesi değişebilir.

$\mathrm{Bu}$ bağlamda denklemlerin klasik standart sapma değerlerinin yanı sıra, bu çalışma kapsamında geliştirilen üç yeni yöntemle değerlendirilmesi gerçekleştirilmiştir. $\mathrm{Bu}$ yöntemlerden ilkinde, gözlemlenen spektral ivme değerlerinin denklemlerle tahmin edilen spektral ivme ile farkının, yani artıkların mutlak değerleri, gözlemlenen ivme değerlerinin normalize edilmesi ile elde edilen ağırlık değerleri ile çarpılarak yeni bir artık değerleri elde edilmiştir (Denklem 1). Böylelikle her bir denklem ve ve belirlenen her spektral periyot için elde edilen artık toplamlarının karşılaştırılması gerçekleştirilmiştir.

$$
I_{\text {artok }}^{t}=\sum_{i=1}^{n} a b s\left(\Delta s a_{i}^{t}\right) I_{w i}^{t}
$$


Denklem 1'de her bir spektral periyot $(t)$ için $I_{\text {arttk }}$ olarak ifade edilen bu toplam, artıkların, $\Delta s a_{i}$, yada gözlemlenen ve tahmin edilen ivme değerleri arasındaki farkın, $I_{w i}$, ağırlık katsayısı ile çarpılarak toplanması ile bulunur. Bu ağırlık katsayıları da, her bir kayıt için gözlemlenen spektral yer ivmelerinin normalize edilmiş değerleri olarak hesaplanır. İkinci yöntemde ise, mutlak artık değerlerinin, deprem merkez üssü ile kayıt istasyonu arasındaki yatay mesafelerin tersi oranında olacak şekilde belirlenen ağırlık katsayılarıyla büyütülerek derlenen yeni artık değerlerinin eklenmesi ile elde edilen toplamların karşılaştırması gerçekleştirilmiştir.

$$
M_{a r t h k}^{t}=\sum_{i=1}^{n} a b s\left(\Delta s a_{i}^{t}\right) M_{w i}^{t}
$$

Denklem 2'de ters mesafe katsayılı artık değeri toplamı, $M_{\text {artk }}, n$ tane kayıt ve belirlenen ve her bir spektral periyot, $t$, için elde edilen artık değerlerinin, $M_{w i}$, ağırlık katsayılarıyla çarpılması sonucu bulunan değerlerin toplanması ile elde edilir.

Üçüncü yöntemde ise, hem ivme değerlerinin hem de mesafenin birlikte önem derecesine göre değerlendirilebileceği eş-ivme haritalarının karşılaştırması yapılır. İvme değerlerinin coğrafi dağılımına göre şekillenecek olan eş-ivme haritasının, denklemlerden hangisi tarafından daha yakın modellendiğini belirleyebilmek için ise, hem kayıtlardan elde edilen ivme değerleri ile geliştirilen ivme-dağılım haritası ile tahmin denklemlerinden elde edilen ivme değerleriyle oluşturulan harita karşılaştırılır.

$$
S=\frac{1}{n} \log \left(\sum_{i j}^{n} R_{i j}\right) \mathrm{ve} \begin{aligned}
R_{i j} & =\left[\frac{X_{i j}}{X_{i j}^{k a y}}\right] \text { eğer } X_{i j} / X_{i j}^{k a y} \geq 1.0 \\
R_{i j} & =\left[\frac{X_{i j}^{k a y}}{X_{i j}}\right] \text { eğer } X_{i j} / X^{k a y}<1.0
\end{aligned}
$$

$\mathrm{Bu}$ karşılaştırma işleminin nicel değerlerini elde etmek için oluşturulan Denklem 3 'te, $S$ değeri benzerlik göstergesini, $R$ benzerlik katsayısını, $X$ değeri de denklemlerden elde edilen eşivme haritası değerlerini göstermekte, $X_{k a y}$ değerleri de kayıtlardan elde edilen eşivme haritası değerlerini temsil etmektedir. Denkleme göre $\mathrm{R}$ değerleri hiçbir zaman 1 değerinden daha düşük olamaz ki, denkleme göre $\mathrm{R}$ değerleri ne kadar çok 1'e yakın olursa o kadar benzeşlik fazla olacaktır. Denkleme göre $\mathrm{S}$ değerleri de ne kadar düşük olursa, benzeşimin o kadar yüksek olacağı bellidir.

\section{CÖZÜMLEME}

Yer hareketinin yayılmasının bütün olası yayılma hatlarda farklılık gösterebileceği gerçeği bu denklemlerin geliştirilmesine engel olmadığ gibi, bu denklemlerin sismik tehlike analizinin olmazsa olmazlarından olduğu düşünülerek, istatistiksel yöntemlerle en uygun denklemin geliştirilmesi ve veritabanının da bu ihtiyaca uygun olarak oluşturulması önem arz etmektedir.
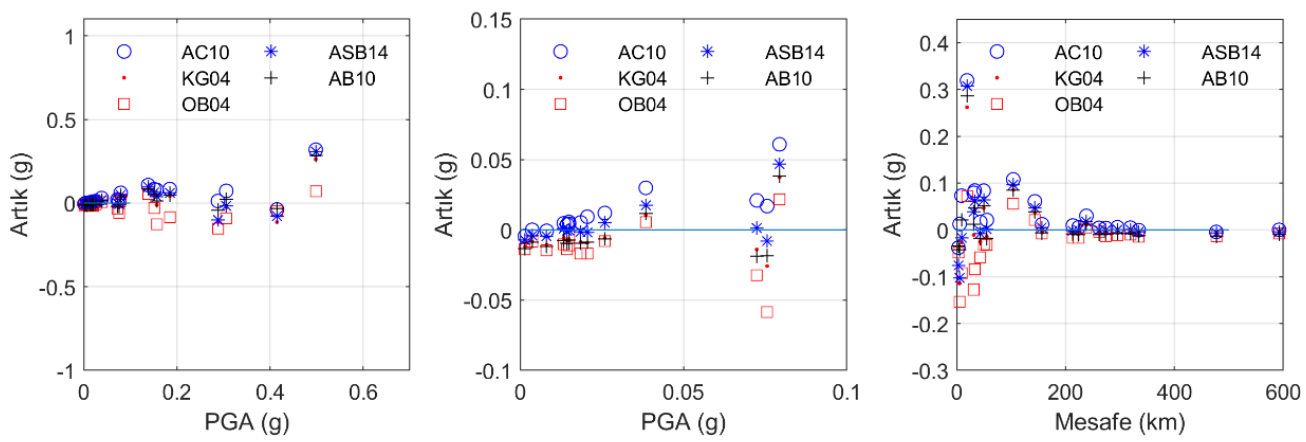

Şekil 2. En büyük yer ivmesi (PGA) ve mesafeye göre artık değerleri dağıllmı. 
Veritabanının zenginliğinin denklemin kesinliği açısından gerekli olduğu bariz olmakla birlikte, bu veriler derlenirken, mühendislik açısından önem arz eden verilerin önceliğinin bulunmaması eksiklik olarak görülmelidir. Veri önceliği ile anlatılmak istenenin daha kolay anlaşılması için Şekil 2'de ki çizimleri incelemek aydınlatıcı olacaktır. PGA değerleri büyüdükçe ve mesafe kısaldıkça artık değerleri de büyümekte, mühendislik açısından önem arz eden veriler için hesaplanan artık değerlerinin, denklemlerin modelleme başarısı açısından diğer artık değerlerinden daha önemli olması gerektiği düşüncesi oluşmaktadır.

Denklemlerin klasik yöntemle karșılaștırılması için geliştirilen göstergelerden en önemlisi ölçüm değerleri ile tahmin değerleri arasındaki yakınlığg ifade etmek için kullanılan benzeşlik katsayısı, R, (korelasyon) ile, $\sigma$, standart sapma değeridir. Şekil 3 'te görüleceği üzere İzmit depremi için OB04 denklemi neredeyse bütün periyotlarda, düşük sapma ve yüksek benzeşim (korelasyon) değerleri il öne çıkarken, Düzce depremi için denklemlerin performansları özellikle düşük periyotlarda birbirine çok yakındır.
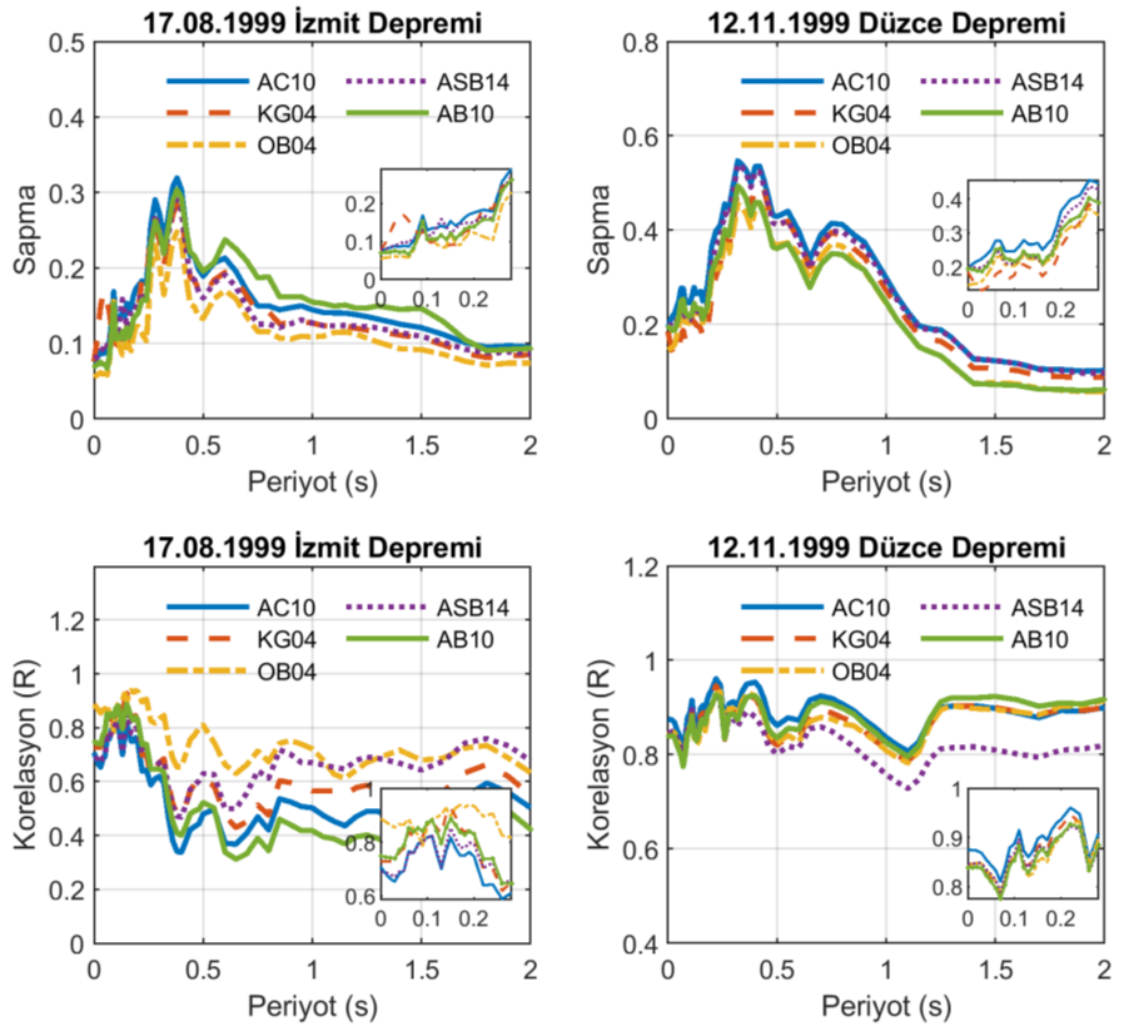

Şekil 3. Standard sapma ve korelasyon katsayısı değerleri. 

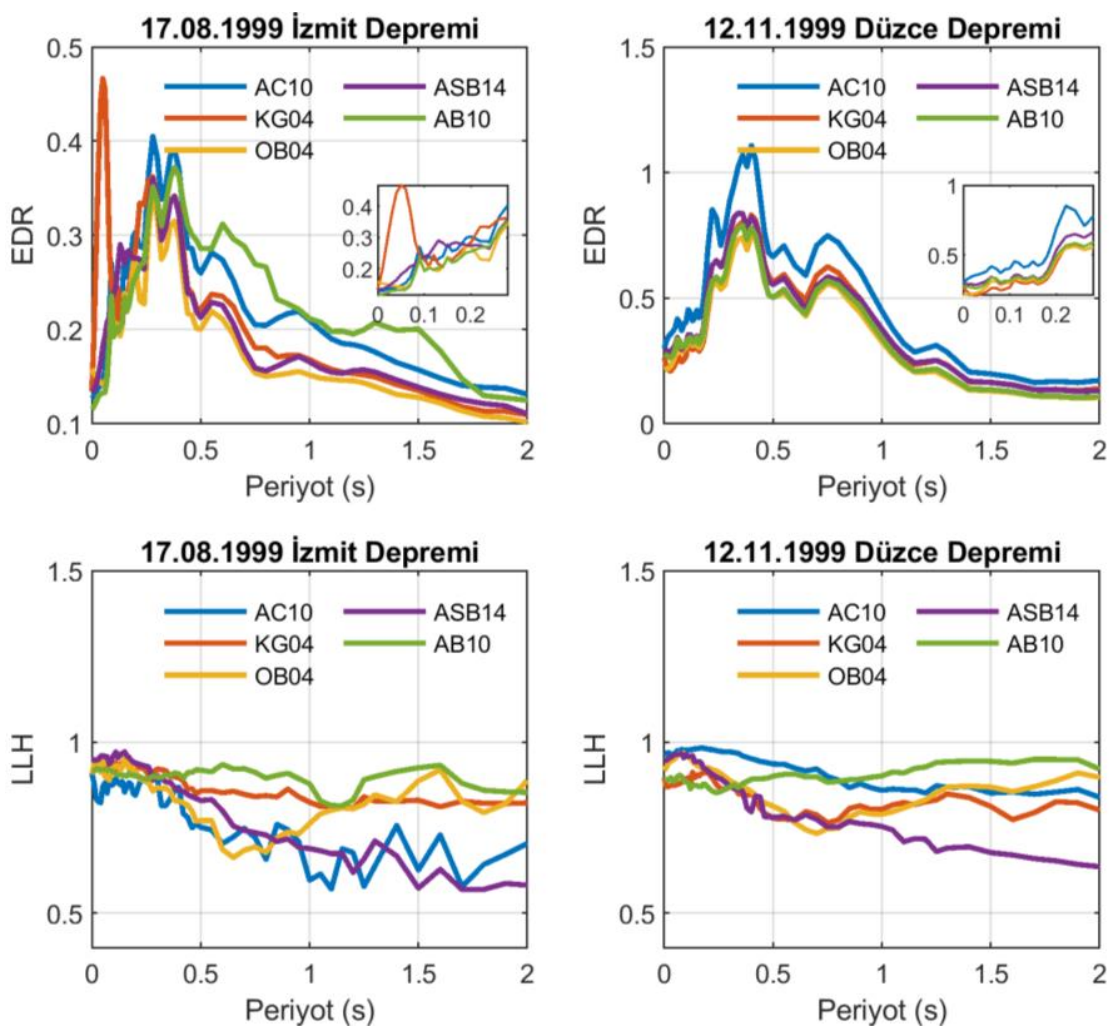

Şekil 4. EDR ve LLH katsayılarının spektral değerleri.

Standart sapma ve benzeşim katsayılarıyla denklemlerin değerlendirilmesinin yanısıra sonuçların pekiştirilmesi ve daha sağlıklı hale getirilmesi amacıyla Scherbaum [29] tarafından geliştirilen LLH yöntemi ile Kale vd. [30] tarafindan geliştirilen EDR yöntemleri de kullanılarak ölçülen ve denklemlerle tahmin edilen değerler arasındaki yanlılığın değerlendirmesi yapılmıştır. Şekil 4 te sonuçları gösterilen çözümlemelere göre de, EDR yöntemine göre de OB04 hem İzmit hem de Düzce deprem verilerinin tahmininde öne çıkmış, düşük periyotlarda ise hem OB04 hem de AB10 diğer denklemlere göre daha az yanlılık göstermişlerdir. LLH verileri ile herhangi bir çıkarıma ulaşmak mümkün değildir.

Aslında klasik yaklaşıma uygun olarak hareket edilirse, sadece Şekil 2'teki artıklar ve Şekil 3'te sunulan değerlerle birlikte yaygın olarak kullanılan yöntemlere başvurularak denklemlerin hangilerinin yerel verilerle daha uyumlu olduğunu kestirmek zor değildir. Ancak böyle bir yaklaşım çalışmanın amacına uygun değildir. Bu bağlamda, ivme orantılı olarak büyütülen artık değerlerinden elde edilen $\mathrm{I}_{\text {artık }}$ değerlerinin dağılımını gösterir Şekil 5 çizimleri incelendiğinde ise, Şekil 3'te verilen $\sigma$ ve $\mathrm{R}$ değerlerine ve Şekil 4 'te sunulan EDR değerlerine göre yapılan değerlendirmenin $\mathrm{I}_{\text {arttk }}$ değerleri için de geçerli olduğu anlaşı1ır. İzmit depremi için 0.1-0.2 s arası hariç OB04 ön plana çıkarken, Düzce depremi için değişken sonuçlar gözlemlenmektedir. Düzce depremi verileri değerlendirildiğinde OB04 ile AB10 denklemlerinin ön plana çıktığı görülmüş, KG04'ün ise özellikle $0.2 \mathrm{~s}$ ve öncesi için belirgin şekilde başarılı olduğu gözlemlenmiştir. 

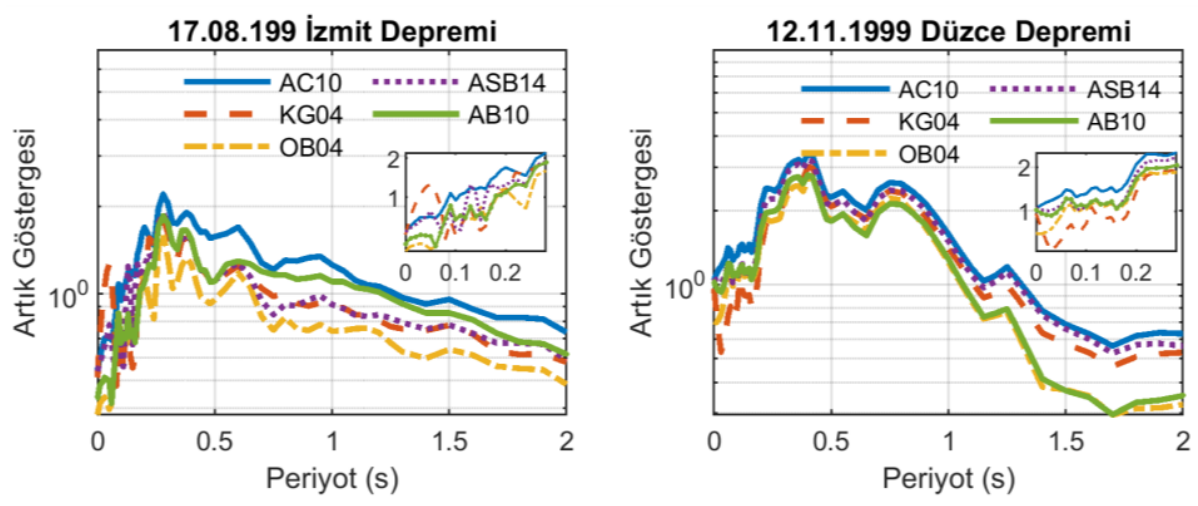

Şekil 5. Artık değerlerinin ivme ile orantılı olarak büyütülmesinden elde edilen Iarth değerleri.

Şekil 6'da $\mathrm{M}_{\text {artık }}$ değerlerinin dağılımı incelendiğinde ise, İzmit depremi için kısa periyotlarda $(0.2 \mathrm{~s}$ ve öncesi) AB10 ve kalan periyotlarda ise OB04'ün ön plana çıtığı, bunun yanı sıra Düzce depremi içinse, Iartık için gözlemlenen sonuçlara benzer sonuçların elde edildiği gözlemlenmektedir. Iartı ve $\mathbf{M}_{\text {artık }}$ değerlerinin aslında birbirleri ile farklı değişkenlere bağlı olarak doğrusal bağı olduğu göz önüne alındığında bu sonucun pek de şaşırtıcı olmadığı da unutulmamalıdır.
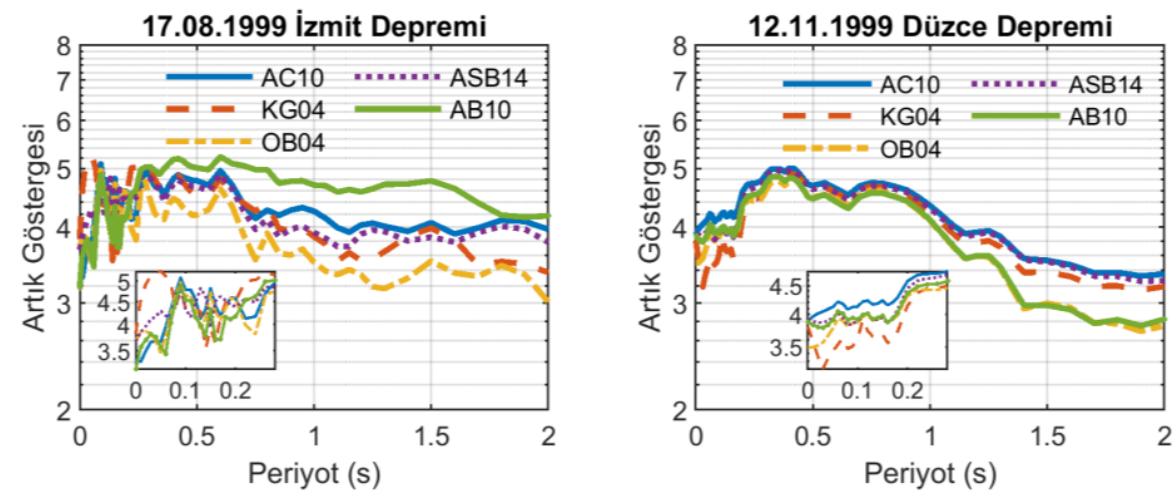

Şekil 6. Artık değerlerinin mesafe ile ters orantılı olarak büyütülmesinden elde edilen $M_{\text {arth }}$ değerleri.

İvme değerlerinin büyüklügü ile orant1lı ve mesafenin tersi ile orantılı olmak üzere yapılan artık değerlendirmelerinin yanısıra, ivme değerlerinin coğrafi dağılımlarının karşılaştırılması hem mesafe hem de ivme büyüklüğünün aynı anda değerlendirilebileceği bir seçenek sunmaktadır. İvme değerlerinin coğrafi dağılımından kastedilen, her bir istasyondan elde edilen ivme değerleri kullanılarak çalışma alanının bütünü için elde edilen ivme dağılımları (eş-ivme) haritasıdır. 

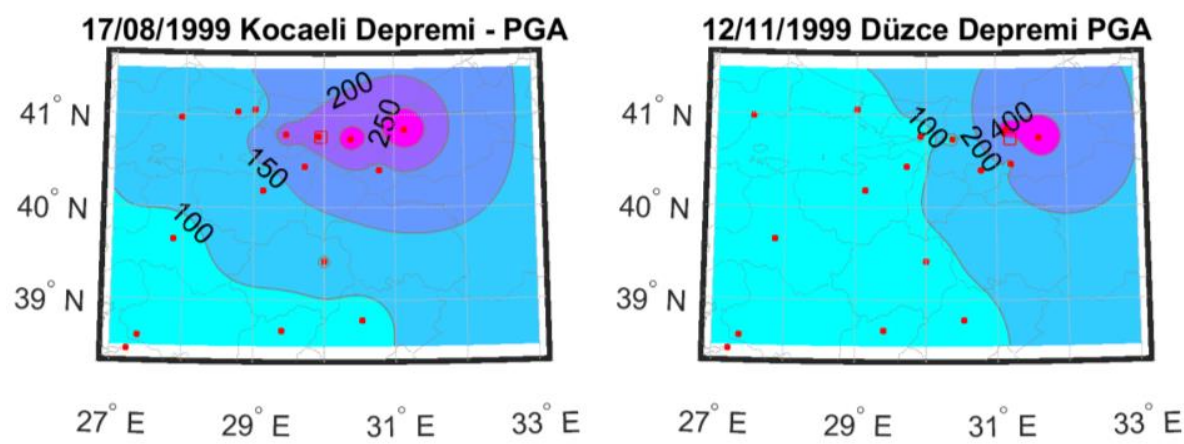

17/08/1999 Kocaeli Depremi $-\mathrm{T}=0.2 \mathrm{~s}$

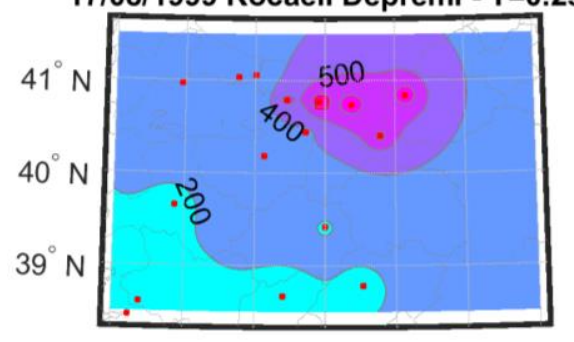

12/11/1999 Düzce Depremi - $\mathrm{T}=0.2 \mathrm{~s}$

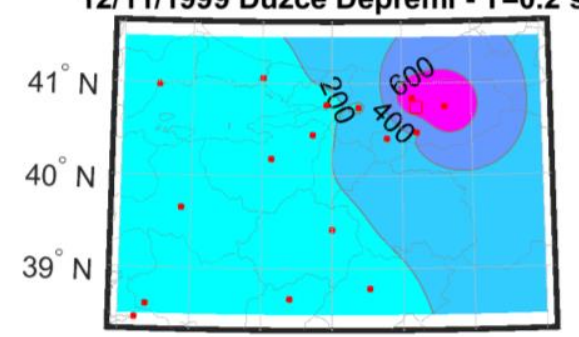

$27^{\circ} \mathrm{E} \quad 29^{\circ} \mathrm{E} \quad 31^{\circ} \mathrm{E} \quad 33^{\circ} \mathrm{E}$

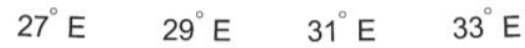

17/08/1999 Kocaeli Depremi - T=1 s
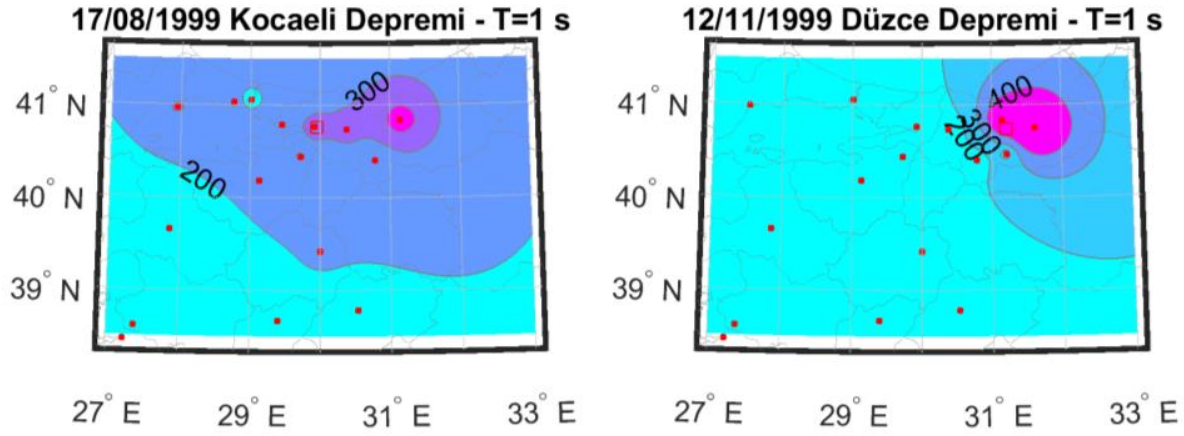

Şekil 7. İzmit ve Düzce deprem kayıtlarından elde edilen eşivme eğrileri.

Şekil 7'de Kocaeli ve Düzce deprem kayıtlarından elde edilen PGA değerleri kullanılarak ve ters uzaklık ağırlıklı ortalama enterpolasyon yöntemi uygulanarak oluşturulan eş-ivme haritası gösterilmektedir. Aslına bakılacak olursa, haritaların ne kadar doğru ya da hâlihazırda düzenlenen eşşiddet haritalarıyla [31] ne kadar benzeştiği soruları bu çalışmanın ana konusu olmaması sebebiyle yanıtlanmamış, asıl anlatılmak istenen yönteme odaklanılmıştır. Ayrıca, zemin parametrelerinin büyütme ve küçültme etkisi nedeniyle enterpolasyon işleminin güvenilirliği de sorgulanmış olup, bu tür büyütme ve küçültme nedeniyle karşılaşılan ivme değişimlerinin, ancak verilerin sayısının artması ile modellenebileceği, alışılagelmiş yöntemlerle de zemin etkisinin modellenmesinin veri azlığında sorunsuz olmayacağı belirtilmelidir.

Bu noktada ayrıca belirtilmelidir ki, ister coğrafi dağılım şeklinde ister alışılagelmiş yöntemlerle değerlendirilsin, bir denklem böyle bir durumu tahmin etmek için gerekli parametreleri de bulundurmalıdır. Özet olarak, eldeki veriler ölçüsünde bir değerlendirme yapılabileceği açık olup, hangi denklemin ne ölçüde bu verileri tahmin edebileceğinin coğrafi dağılım yöntemiyle de yapılabileceği ve hatta bu yöntemin daha güçlü bir değerlendirme olanağı sunduğu anlaşılabilir. Sonuç olarak bu yöntemin uygunluğu düşünülerek çözümlemeler gerçekleştirilmiş ve denklemlerden elde edilen ivme haritalarının kayıtlardan elde edilen ivme haritaları ile benzeşimini belirlemek için 3 no'lu denklem kullanılmış ve her bir periyot için belirlenen S değerleri hesaplanmıştır. Şekil 7'de sunulan S değerleri en başarılı YHTD olarak İzmit Depremi için OB04'ü işaret ederken, Düzce depremi için 0$0.4 \mathrm{~s}$ arası $\mathrm{OB} 04$ ve geri kalan periyotlarda da AB10'u işaret etmektedir. AC10 ve ASB14 için hesaplanan S değerlerinin çok yüksek olması, bu iki denklem kullanılarak elde edilen ivmelerin 
coğrafi dağılımının, Şekil 6'da verilen coğrafi dağılım haritalarıyla pek de uyuşmadığını göstermektedir.

Şekil 5,6 ve 8'de sunulan göstergelerden bir çıkarım yapmak gerekirse, OB04'ün diğer YHTD'lere göre daha başarılı olarak ön plana çıktığı, bunun yanısıra KG04 ve AB10 denklemlerinin de İzmit ve Düzce deprem etkilerinin yayılma desenlerini göreceli olarak daha başarılı bir şekilde tahmin ettiği söylenebilir.
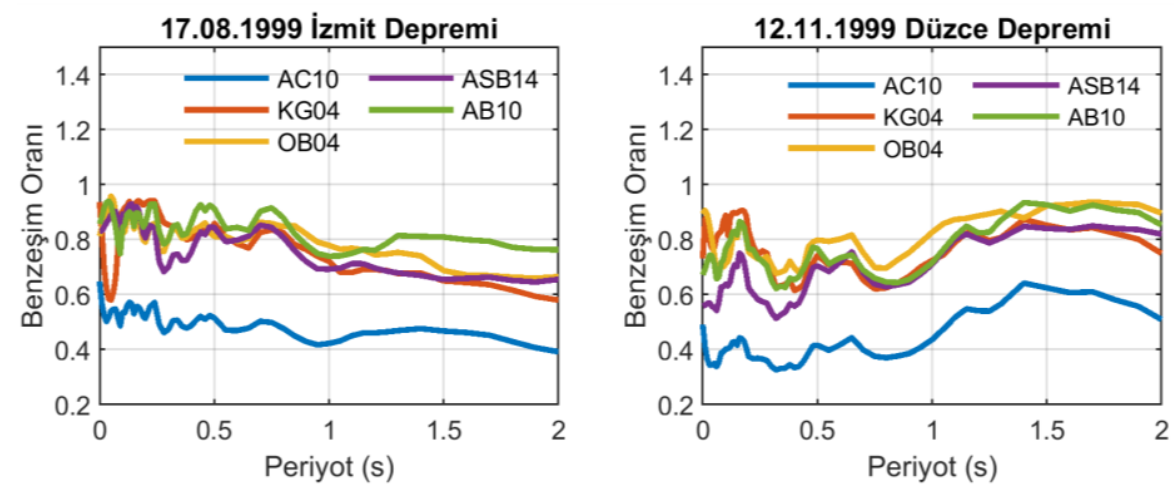

Şekil 8. Harita benzeşim göstergeleri, S.

\section{IV.SONUC}

Yer hareketi tahmin denklemleri deprem büyüklüğü, periyot, mesafe ve zemin özelliklerine bağl1 olarak ivme değerlerini tahmin etmek üzere geliştirilirler. Denklemin en doğru şekilde oluşturulabilmesi için kullanılan veritabanının zengin olması aranır. Verilerin çokluğu hem genel belirsizliği hem de denklemi oluşturan terimlerin katsayılarının belirsizliğini azaltır.

Ancak şurası da unutulmamalıdır ki, verilerin çokluğu denklemin kesinliği hakkında belirsizliği azaltırken, denklemi oluşturan terimlerin artmasına ve dolayısıyla da verilere bağımlılığı artırmakla birlikte verilerin dışında kalan diğer verilerle ilgili olarak modelleme garantisi de verememektedir. Bunun üzerine bir de yer hareketi yayılma desenlerinin yerelliği ile ilgili varsayımlarda eklendiğinde, denklemlerin terim sayısının çokluğu ya da veri tabanının büyüklüğünün, denklemlerin uygulanabilirliğini sağlayamayabileceği beklenmelidir.

Hâlihazırda geliştirilen denklemler için geniş veritabanları oluşturulduğu [1] ve bu veritabanlarında da hem deprem büyüklüğü hem de mesafe aralıklarının düzenli dağılımı açısından yeterli sayıda örnek bulunduğu bir gerçektir. Bu durum karşısında, yer hareketlerinin mesafeye ve depremin büyüklüğüne göre nasıl bir değişim gösterdiği aslında bilinebilir. Dolayısıyla, zaten hâlihazırdaki veri tabanlarında kuvvetli yer hareketlerinin kısa mesafelerde yayılma eğilimleri hakkında bilgi sahibi olunabildiği halde, neden bu verileri yalıtıp yeniden bir değerlendirme yapılsın denilebilir. Böyle bir soru karşısında verilebilecek yanıt da sorunun kendisinde gizlidir ki, veritabanlarının büyük olması ve deprem büyüklüğü ve mesafe açısından düzenli bir dağılıma sahip olması, çalışmada odaklanılan yer hareketleri ile ilgili yanlılığa neden olma olasılığı yüksektir. Yani büyük veritabanı içersinde, çalışmaya konu olan yer hareketlerinin ağırlığı kadar denklemin oluşmasına etki edeceği açıktır. Büyük veri tabanlarının belki de, küçük bir kısmını oluşturan kuvvetli yer hareketlerinin kısa mesafe yayılma özellikleri, aslında o kadar önemli olmakla birlikte, belirgin bir şekilde genel yayılma özelliklerinden farklıdır. Böyle bir durumda bu çalışmanın yapılmasının ne kadar önemli olduğu açıktır.

Bu bağlamda çalışmada elde edilen sonuçlardan belki de en önemlisi, denklemleri geliştirebilmek için kullanılan veri tabanının özelliklerine göre şekillenen denklemlerin, bu veri tabanlarına olan bağımlılı̆̆ının, denklemlerin tahmin yetisine direk olarak etki ettiğinin gösterilmesidir. İzmit ve Düzce deprem kayıtlarının ağırlığının fazla olduğu OB04 ile KG04 ve veri tabanı sınırları açısından göreli 
olarak büyük depremlerin küçük mesafelerde yayılmasını modellemeyi amaçlayan AB10 denkleminin öne çıkması rastlantı değildir. Özellikle yerellik ve ölçüm yanlılığı hususları göz önüne alındığında, denklemleri oluşturup değişken katsayılarını elde ederken kullanılacak olan veri tabanlarının hem mesafe hem de deprem büyüklüğü açısından daha odaklı olmaları gerektiği de belirtilmesi gereken ikinci bir husustur.

\section{V.KAYNAKLAR}

[1] J. Douglas, (2019, 26 Haziran). Ground motion prediction equations [Çevirimiçi]. Erişim: http://www.gmpe.org.uk.

[2] J. Douglas and D. M. Boore, "Peak ground accelerations from large (M > 7.2) shallow crustal earthquakes: a comparison with predictions from eight recent ground-motion models," Bulleting of Earthquake Engineering, vol. 16, no.1, pp-1-21, 2018.

[3] J. Douglas and B. Edwards, "Recent and future developments in earthquake ground motion estimation," Earth Science Reviews, vol.160, pp. 203-219, 2016.

[4] J. P.Stewart, J. Douglas, M. Javanbarg, N.A. Abrahamson, Y. Bozorgnia, D.M. Boore, K.W. Campbell, E. Delavaud, M. Erdik and P.J. Stafford, "Selection of ground motion prediction equations for the Global Earthquake Model,” Earthquake Spectra, vol. 31, no.1, pp. 19-45, 2015.

[5] D.M. Boore and G. Atkinson, "Ground motion prediction equations for the average horizontal component of PGA, PGV and \%5-damped PSA at spectral periods between $0.01 \mathrm{~s}$ and $10.0 \mathrm{~s}$," Earthquake Spectra, vol. 24, no. 1, pp. 99-138, 2010.

[6] AFAD, (2019, 20 Haziran). Afet ve Acil Durum Yönetimi Başkanlığı Deprem Dairesi Başkanlığı [Çevirimiçi]. Erişim: https://deprem.afad.gov.tr/

[7] S. Akkar, Z. Cagnan, E. Yenier, Ö. Erdoğan, A. Sandıkkaya and P. Gulkan, "The recently compiled Turkish strong motion database: preliminary investigation for seismological parameters, " journal of Seismology, vol.14, no.3, pp. 457-479, 2010.

[8] M. A. Sandıkkaya, M.T. Yılmaz, B. S. Bakır and Ö. Yılmaz, "Site Classification of Turkish Natioanl Strong-Motion Stations,” Journal of Seismology, vol. 4, pp. 543-563, 2010.

[9] P.Y. Bard, S.S. Bora, F. Hollender, A. Laurendeau and P. Traversa. "Are the standard $\mathrm{V}_{\mathrm{s} 30}$ kappa host-to-target adjustments the best way to get consistent hard- rock ground motion prediction?. Best Practices in Physics-based Fault Rupture Models for Seismic Hazard Assessment of Nuclear Installations: issues and challenges towards full Seismic Risk Analysis," CEA - AIEA, Cadarache France, 2018.

[10] O. Kale, S. Akkar, A. Ansari and H. Hamzehloo, "A ground-motion predictive model for Iran and Turkey for horizontal PGA, PGV, and 5\% damped response spectrum: Investigation of possible regional effects," Bulletin of Seismological Society of America, vol. 105, no. 2, pp. 963-980, 2015.

[11] N.M. Kuehn and F. Scherbaum, "A partially non-ergodic ground-motion prediction equation for Europe and the Middle East," Bulletin of Earthquake Engineering, vol.14, no.10, pp. 2629-2642, 2016.

[12] O.J. Ktenidou, Z. Roumelioti, N. Abrahamson, F. Cotton, K. Pitilakis and F. Hollender, "Understanding single-station ground motion variability and uncertainty (sigma): lessons learnt from EUROSEISTEST," Bulletin of Earthquake Engineering, vol.16, no. 6, pp. 2311-2336, 2017.

[13] S.R. Kotha, D. Bindi and F. Cotton, "Partially non-ergodic region specific GMPE for Europe 
and Middle-East," Bulletin of Earthquake Engineering, vol. 14, no. 4, pp. 1245-1263, 2016.

[14] D. Bindi, D. Spallarossa and F. Pacor, "Between-event and between-station variability observed in the Fourier and response spectra domains: comparison with seismological models," Geophysical Journal International, vol. 210, no. 2, pp. 1092-1104, 2017.

[15] Z. Gülerce, B. Kargioglu and N.A. Abrahamson, "Turkey-adjusted NGA-W1 horizontal ground motion prediction models," Earthquake Spectra, vol. 32, pp. 75-100, 2015.

[16] E. Yenier, "Regionally-adjustable generic ground-motion prediction equation," Ph.D. dissertation, University of Western Ontario, Ontario, Canada, 2015.

[17] H. Karaca, "Güncel veriler ve olasılıksal sismik tehlike analizi kullanarak eskişehir için sismik tehlike haritası ve ivme eğrileri elde edilmesi," Journal of the Faculty of Engineering and Architecture of Gazi University, c. 32, s.1, ss. 243-251, 2017.

[18] E. Kalkan and P. Gülkan, "Site-dependent spectra derived from ground motion records in Turkey," Earthquake Spectra, vol. 20, no. 4, pp. 1111-1138, 2004.

[19] C. Özbey, A. Sari, L. Manuel, M. Erdik and Y. Fahjan, "An empirical attenuation relationship for northwestern Turkey ground motion using a random effects approach," Soil Dynamics and Earthquake Engineering, vol. 24, no. 2, pp. 115-125, 2004.

[20] S. Akkar and Z. Cağnan, "A local ground motion predictive model for Turkey and its comparison with other regional and global ground-motion models," Bulletin of Seismological Society of America, vol. 100, pp. 2978-2995, 2010.

[21] S. Akkar and J. J. Bommer, "Empirical equations for the prediction of PGA, PGV and spectral accelerations in Europe, the Mediterranean region and the Middle East", Seismological Research Letters, vol. 81, no. 2, pp.195-206, 2010.

[22] S. Akkar, M.A. Sandıkaya and J. J. Bommer, "Empirical ground-motion models for pointand extended-source crustal earthquake scenarios in Europe and the Middle East," Bulletin of Earthquake Engineering, vol. 12, no.1, pp. 359-387, 2014.

[23] S. Akkar, Ö. Kale, A. Yakut and U. Çeken, "Ground-motion characterization for the probabilistic seismic hazard assessment in Turkey," Bulletin of Earthquake Engineering, vol. 16, no. 8, pp. 3439-3463, 2017.

[24] Ö. Kale, "Some discussions on data-driven testing of ground-motion prediction equations under the turkish ground-motion database," Journal of Earthquake Engineering, pp. 1-22, 2017.

[25] D. Bindi, S. Parolai, H. Grosser, C. Milereit and E. Durukal, "Empirical ground-motion prediction equations for the northwestern turkey using the aftershocks of the 1999 Kocaeli earthquake," Geophysical Research Letters, vol.34, no. L08305, 2007.

[26] P. Gulkan, "Expecting the expected: 1 g peak motions in the automated damage detection," Presented in 15th World Conference on Earthquake Engineering, Lisbon, 2012.

[27] A. Akınc1, "Strong ground Motion Characteristics from the 17 August 1999 Kocaeli, Turkey Earthquake," Bollettino Di Geofisica Teorica Ed Applicata, vol. 43, no.2, pp.37-52, 2002.

[28] E. Durukal, "Critical evaluation of strong motion in Kocaeli and Düzce (Turkey) earthquakes," Soil Dynamics and Earthquake Engineering, vol. 22, pp. 589 - 609, 2002.

[29] F. Scherbaum, E. Delavaud and C. Riggelsen, "Model Selection in Seismic Hazard Analysis: 
An Information-theoretic Perspective," Bulletin of Earthquake Engineering, vol. 99, pp. 3234-3247, 2009.

[30] Ö. Kale and S. Akkar, "A new procedure for selecting and ranking ground-motion prediction equations (GMPEs): the euclidean-distance based ranking (EDR) method," Bulletin of Earthquake Engineering, vol.103, pp. 1069-1084, 2013.

[31] B. Özmen, "17 Ağustos 1999 İzmit Körfezi Depremi Eş-Şiddet Haritası, 17 Ağustos 1999 İzmit Körfezi Deprem Raporu,” Bayındırlık ve İskân Bakanlığı Afet İşleri Genel Müdürlüğü Deprem Araştırma Dairesi Başkanlığı, Ankara, Türkiye, 2000. 